\title{
EFFECTS OF JUDO PARTICIPATION ON ANTHROPOMETRIC CHARACTERISTICS, MOTOR ABILITIES, AND POSTURE IN YOUNG JUDO ATHLETES
}

original paper

( ) University School of Physical Education in Wroclaw

DOI: https://doi.org/10.5114/hm.2019.83992

\author{
BRANKA PROTIC-GAVA ${ }^{1}$, PATRIK DRID ${ }^{1}$, ZARKO KRKELJAS ${ }^{2}$ \\ ${ }^{1}$ University of Novi Sad, Novi Sad, Serbia \\ ${ }^{2}$ Stellenbosch University, Stellenbosch, South Africa
}

\section{ABSTRACT}

Purpose. Despite the benefits of sport participation to schoolchildren, some highly competitive activities may induce sportspecific physical adaptations that may predispose children to long-term motor impairments. Hence, the aim of this study was to compare the anthropometric characteristics, motor abilities, and posture between schoolchildren actively participating in judo and their peers participating in general physical education classes.

Methods. The study included 148 male participants aged 12-14 years. The two groups of subjects were compared in terms of their anthropometrics, posture, and motor abilities.

Results. Statistically significant differences were observed in subscapular skinfold and triceps skinfold in favour of the young judokas. Judo competitors also demonstrated better functional coordination, flexibility, explosive force of lower limbs, and pelvic and isometric muscular endurance. In addition, judokas were characterized by better postural alignment relative to shoulders, chest, and abdomen.

Conclusions. The results suggest that participation in judo in addition to physical education classes builds specific motor and physical characteristics in children that may aid in healthy body development.

Key words: judo, physical education, motor abilities, posture

\section{Introduction}

Physical activity is a crucial component of physical and mental development of children. Participation in general or sport-specific activity improves body composition [1, 2], posture [3-5], and physical fitness [1, 6-9] and it significantly contributes to the development and refining of motor coordination and skills [1, 2, 7]. However, exposing young athletes to repetitive training in a high competitiveness environment may also lead to physical impairments and consequently hinder proper physical development [10-12]. Hence, it is imperative to assess the effects of participation in different types of activities on children's physical and motor development.

Judo is one of the most popular martial arts in the world, and is among the safest contact sports for children [13]. With equal focus on mental, physical, and moral development, judo has become an integral part of physical education programs in most Asian countries [9]. In addition to safety, several studies have found multiple advantages of judo participation for young players. Firstly, training martial arts encourages overall physical development, including flexibility, explosive strength, balance, agility, and motor coordination [14]. Consequently, young judo athletes exhibit greater handgrip strength, jump height, and pull-up performance relative to their non-judo peers [6, 9]. Interestingly, some research shows that aerobic capacity in judo competitors is greater than that of soccer players or gymnasts [8], and that experienced judokas have better postural control than ballet dancers [15].

However, judo also entails frequent falling on the back (i.e. break falls) and exercises while carrying a partner [9]. Further progression of these techniques includes isometric holds with sparring exercises and

Correspondence address: Zarko Krkeljas, Duke Kunshan University, 6 Duke Avenue, Kunshan, Jiangsu, China 215316, e-mail: zarkokrkeljas@gmail.com

Received: November 6, 2018

Accepted for publication: January 30, 2019

Citation: Protic-Gava B, Drid P, Krkeljas Z. Effects of judo participation on anthropometric characteristics, motor abilities, and posture in young judo athletes. Hum Mov. 2019;20(3):10-15; https://doi.org/10.5114/hm.2019.83992. 
body throws [9]. Although these are taught early in the training process in order to educate beginners on safe practices in judo, they still involve repetitive movements with high loads, which, as indicated earlier, may result in altered motor control [16], injury, and postural disorders.

While many studies have been dedicated to evaluating physical characteristics of young and experienced martial artists, to our knowledge, there is limited research on postural assessment of young judokas relative to their peers. Therefore, the primary aim of this study was to compare anthropometric characteristics, motor abilities, and posture in young judokas and their counterparts. The results may be used to recommend the implementation of specific exercises within the training process of young judo athletes, and inclusion of judo as a potential physical development strategy in schools.

\section{Material and methods}

\section{Subjects}

This is a simple comparative, observational study. Two groups of schoolchildren were assessed for anthropometric and physical characteristics; one group participated in judo and physical education classes, and the other one only in physical education classes. The participants were recruited from local judo clubs and elementary schools. The subjects and their parents were fully informed about the nature and purpose of the study.

A sample of 148 male children aged $12-14$ years participated in the study and were divided into 2 groups: the judo group ( $n=58$; age: $12.9 \pm 0.43$ years; height: $157.6 \pm 11.5 \mathrm{~cm}$; body mass: $51.1 \pm 1.9 \mathrm{~kg}$ ) and the non-judo group ( $n=90$; age: $13.02 \pm 0.39$ years; height: $161.6 \pm 10.6 \mathrm{~cm}$; body mass: $51.4 \pm 1.2 \mathrm{~kg}$ ). The inclusion criteria were no diagnosis of any chronic musculoskeletal problem, no medication taken, and no immobilization or injury of any part of the body within 6 months prior to the measurement. The participants in the judo group had to have continually attended judo training for at least 3 years (at least 2 times per week with 60-minute sessions), with at least 6 months of continuous training prior to the measurement. Both groups participated in regular physical education classes in their schools.

\section{Procedures}

The participants completed 9 anthropometric [17], 8 motor [18], and 8 postural tests [19-21], assessed by a team of experienced examiners of the Department of Sport and Physical Education at University of Novi Sad. All participants were dressed in general sports clothing and were barefoot. Separate instructors were assigned for each test to minimize measuring bias.

\section{Anthropometric measures}

The following anthropometric measurements were completed in accordance with the standards and procedures set in the International Biological Program [17]: body height and mass, chest circumference, upper arm circumference, forearm circumference, abdominal circumference, triceps skinfold, subscapular skinfold, and abdominal skinfold.

\section{Motor ability}

All motor ability tests were performed in accordance with the EUROFIT battery of tests for physical readiness [18]. The participants were divided into 8 groups (1 group per test). Prior to data collection, an instructor explained and demonstrated the test and the subjects were given an opportunity to try the test before the recorded trials. After all participants completed their tests, there was a 3-minute rest prior to changing stations, and the children were tested in the same order as in the previous test. All times were measured with a generic stopwatch to the nearest 0.1 second.

Flexibility was assessed by the sit-and-reach test and recorded to the nearest $0.1 \mathrm{~cm}$ [2]. To evaluate the explosive leg power, standing horizontal jump and 20-m dash were performed. During the horizontal jump, the participants were able to use their hands and were instructed to 'stick the landing,' and land on the scale pre-marked on the floor. Jump distance was measured to the nearest $0.1 \mathrm{~cm}$. During the 20 -meter sprint, the subjects were instructed to start the sprint on the 'go' command and cover the distance between two 20-meter lines as fast as possible. The speed of hand movement was determined via the plate tapping test. The participants positioned their non-preferred hand on the table equidistant from two discs 60-cm apart. On the 'go' command, they had to tap the disks as fast as possible for 15 seconds by moving their hand between the discs and over the stationary hand. The number of taps was recorded. Abdominal strength was measured via the sit-up test, where the children had to perform as many sit-ups as possible in $60 \mathrm{sec}-$ onds. Starting position required them to lie on their back with hands crossed on their chest, feet flat on the floor, and knees flexed at the right angle. The flexed 
arm hang test was performed to assess upper body strength and endurance. The subjects were helped into position on a horizontal bar, holding an overhand grip, shoulder width apart and the chin above the bar. They were asked to maintain this position as long as possible. The time started when the participants were released. Obstacle and slalom courses were designed for this study in order to assess functional coordination. Firstly, for the obstacle course, the children were asked to walk backwards 10 meters on their hands and feet (i.e. 'on-all-fours') without their knees touching the ground and then climb over and immediately slide under a 'Swedish bench' (height: $34 \mathrm{~cm}$ ) positioned at the 10-meter end line. The slalom course required the participants to roll 3 medicine balls simultaneously $(1 \mathrm{~kg})$ at the length of 10 meters while manoeuvring between 5 cones positioned 2 meters apart.

\section{Posture}

The total body posture was evaluated on the basis of head and shoulder posture, development of chest, scapular position, spinal curvature in the sagittal plane, shape of abdominal wall, knee and foot alignment $[19,21]$. The grading of segmental deviations and methods of evaluation were explained in detail by Wolański [19] and further validated by Wurth [20]. The magnitude of postural or structural deviations was ranked as 0 (no deviations), 1 (some deviation), or 2 (clear/distinct deviation) [19, 20].

\section{Statistical analysis}

The SPSS for Windows statistical software, version 20.0, was used for statistical analysis. Multivariate analysis of variance (MANOVA) was applied to calculate differences between groups for anthropometric and motor tests while chi-square test served to evaluate differences in posture. The level of statistical significance was set as $\alpha=0.05$.

\section{Ethical approval}

The research related to human use has been complied with all the relevant national regulations and institutional policies, has followed the tenets of the Declaration of Helsinki, and has been approved by the University of Novi Sad Ethics Committee.

\section{Informed consent}

Informed consent has been obtained from all individuals included in this study and their legal guardians.

\section{Results}

There were no significant differences between groups in height, weight, or limb circumference. However, the participants in the judo group had significantly less subcutaneous fat on the back (subscapular skinfold) and the upper arm (triceps skinfold) compared with their peers in the non-judo group $(p<0.05)$ (Table 1$)$.

With regard to motor performance (Table 2), judokas displayed significantly better overall motor performance $(F=3.86, p<0.01)$. Specifically, they scored significantly better on functional coordination, flexibility, explosive power, and upper body muscular endurance $(p<0.001)$. Although there were noted differences in slalom and abdominal strength, they were not statistically significant.

Evaluation of posture (Table 3) also shows significant differences between the judokas and their nonathlete peers. Those participating in judo had better shoulder posture, development of chest, and abdominal alignment $(p<0.05)$. Interestingly, children from the non-judo group showed smaller deviation in knee alignment $(p<0.05)$.

Table 1. Differences in anthropometric variables between groups

\begin{tabular}{lcccc}
\hline & Judo & PE only & $F$ & $p$ \\
\hline Body height (cm) & $157.6 \pm 11.5$ & $161.6 \pm 10.6$ & 1.93 & 0.06 \\
Body mass (kg) & $51.1 \pm 1.4$ & $51.4 \pm 1.2$ & 1.50 & 0.16 \\
Chest circumference (cm) & $77.3 \pm 8.4$ & $75.5 \pm 9.7$ & 1.27 & 0.26 \\
Upper arm circumference (cm) & $23.1 \pm 3.4$ & $22.8 \pm 3.3$ & 1.81 & 0.08 \\
Forearm circumference (cm) & $21.6 \pm 2.8$ & $21.5 \pm 2.2$ & 1.09 & 0.38 \\
Abdominal circumference (cm) & $71.2 \pm 9.4$ & $70.7 \pm 9.0$ & 1.34 & 0.23 \\
Triceps skinfold (mm) & $9.8 \pm 3.7$ & $11.9 \pm 6.1$ & 2.34 & $0.02^{*}$ \\
Subscapular skinfold (mm) & $9.3 \pm 5.5$ & $9.7 \pm 6.4$ & 2.68 & $0.01^{*}$ \\
Abdominal skinfold (mm) & $14.9 \pm 10.1$ & $15.0 \pm 9.0$ & 1.63 & 0.12 \\
\hline
\end{tabular}

$\mathrm{PE}$ - physical education, ${ }^{*} p<0.05$ 
Table 2. Differences in motor performance between groups

\begin{tabular}{lcccc}
\hline & Judo & PE only & $F$ & $p$ \\
\hline 20-m sprint (s) & $40.4 \pm 4.2$ & $40.8 \pm 3.3$ & 1.47 & 0.16 \\
Obstacle course (s) & $123.0 \pm 41.5$ & $157.7 \pm 54.6$ & 3.73 & $<0.01^{*}$ \\
Slalom (s) & $379.0 \pm 93.3$ & $338.8 \pm 60.0$ & 1.06 & 0.40 \\
Hand speed (freq.) & $26.9 \pm 4.3$ & $29.7 \pm 4.4$ & 1.74 & 0.09 \\
Sit-and-reach (cm) & $43.2 \pm 8.8$ & $42.7 \pm 8.3$ & 3.53 & $<0.01^{*}$ \\
Standing jump (cm) & $183.2 \pm 24.7$ & $180.3 \pm 25.7$ & 4.51 & $<0.01^{*}$ \\
Arm hang (s) & $460.7 \pm 300.3$ & $367.6 \pm 229.5$ & 5.52 & $<0.01^{*}$ \\
Sit-ups (freq.) & $45.1 \pm 9.8$ & $41.2 \pm 8.6$ & 1.85 & 0.06 \\
\hline
\end{tabular}

$\mathrm{PE}$ - physical education, * $p<0.05$

Table 3. Differences between groups in the distribution of scores for postural evaluation

\begin{tabular}{|c|c|c|c|c|c|}
\hline & \multirow{2}{*}{ Score } & \multicolumn{2}{|c|}{ Frequency (\%) } & \multirow{2}{*}{$\chi^{2}$} & \multirow{2}{*}{$p$} \\
\hline & & Judo & PE only & & \\
\hline \multirow{3}{*}{ Head position } & 0 & 70.7 & 58.9 & \multirow{3}{*}{2.56} & \multirow{3}{*}{0.28} \\
\hline & 1 & 24.1 & 36.7 & & \\
\hline & 2 & 5.2 & 4.4 & & \\
\hline \multirow{3}{*}{ Shoulder posture } & 0 & 62.1 & 35.6 & \multirow{3}{*}{10.11} & \multirow{3}{*}{$0.01^{*}$} \\
\hline & 1 & 36.2 & 60.0 & & \\
\hline & 2 & 1.7 & 4.4 & & \\
\hline \multirow{3}{*}{ Chest development } & 0 & 96.6 & 81.1 & \multirow{3}{*}{11.06} & \multirow{3}{*}{$<0.01^{*}$} \\
\hline & 1 & 1.7 & 18.9 & & \\
\hline & 2 & 1.7 & 0.0 & & \\
\hline \multirow{3}{*}{ Scapular position } & 0 & 50.0 & 34.4 & \multirow{3}{*}{4.47} & \multirow{3}{*}{0.11} \\
\hline & 1 & 50.0 & 63.3 & & \\
\hline & 2 & 0.0 & 2.2 & & \\
\hline \multirow{3}{*}{ Spinal alignment } & 0 & 63.8 & 76.7 & \multirow{3}{*}{2.88} & \multirow{3}{*}{0.24} \\
\hline & 1 & 34.5 & 22.2 & & \\
\hline & 2 & 1.7 & 1.1 & & \\
\hline \multirow{3}{*}{ Abdominal wall } & 0 & 60.3 & 34.4 & \multirow{3}{*}{9.62} & \multirow{3}{*}{$0.01 *$} \\
\hline & 1 & 29.3 & 50.0 & & \\
\hline & 2 & 10.3 & 15.6 & & \\
\hline \multirow{3}{*}{ Knee alignment } & 0 & 69.0 & 87.8 & \multirow{3}{*}{10.54} & \multirow{3}{*}{$<0.01^{*}$} \\
\hline & 1 & 27.6 & 7.8 & & \\
\hline & 2 & 3.4 & 4.4 & & \\
\hline \multirow{3}{*}{ Foot alignment } & 0 & 60.3 & 54.4 & \multirow{3}{*}{2.61} & \multirow{3}{*}{0.27} \\
\hline & 1 & 37.9 & 37.8 & & \\
\hline & 2 & 1.7 & 7.8 & & \\
\hline
\end{tabular}

$\mathrm{PE}$ - physical education, ${ }^{*} p<0.05$

\section{Discussion}

The results of this study demonstrate that participation in judo results in an increased motor performance and better posture among schoolchildren. Previous research has demonstrated similar findings for various individual and team sports; however, this is one of the few studies assessing the effect of judo training among schoolchildren as compared with those participating in physical education classes only.

Firstly, judo competitors demonstrated better flexibility, lower leg power, and upper body strength relative 
to their peers participating only in physical education classes. These results are in agreement with previous findings, which however, compared children participating in judo with their non-active peers [6] and with other sports athletes [22]. More importantly, the development of these motor characteristics in children practising judo has been linked to a steadier rate of motor development than that observed in their healthy non-judo peers [9, 23]. As both groups of children were considered of healthy weight on the basis of their BMI, these improvements in motor characteristics may be attributed solely to the benefits of judo training.

Interestingly, as for functional coordination, judokas were significantly faster than the physical education group on the obstacle course, but in the slalom, where they had to coordinate their movement and ball control, the differences in times were not statistically different. These results likely stem from the development of sport-specific skills in children who participate in one sport for a prolonged period of time. In this study, judo participants had regularly practised this discipline for at least 3 years, which could essentially lead to the development of sport-specific characteristics in flexibility, strength, and power [9, 14, 22, 23], whereas ball handling skills are not relevant to judokas' activity.

The results of this study also show that young judo athletes had better shoulder posture, chest development, and alignment of the abdominal wall as compared with their peers. Although there are limited studies that evaluated comprehensive changes in posture relative to participation in sport activities, judo in particular, Coelho et al. [4] found that general physical activity led to better shoulder posture and body alignment in schoolchildren, while Grabara [11] observed that children practising soccer only had more symmetric pelvis with no other differences in posture as compared with their untrained peers. Considering that the rate of motor development in young judo athletes has shown to be steadier than among healthy controls for this age group [24], the development of the previously discussed physical characteristics also contributes to the correct formation of the morphological structure of the body and is especially crucial for growth and development. Hence, participation in judo, in addition to physical education classes, may result in better posture and body development.

Furthermore, the results also demonstrate that in addition to sport-specific motor development, children may also go through sport-specific postural adaptations. For example, in this study, improvements in upper body strength, abdominal strength, and endurance coincide with better shoulder alignment and abdominal deviations. Similarly, Grabara [11] shows that children participating in soccer displayed only better pelvic symmetry, while there were no other differences in posture between them and their non-active peers. Therefore, although the development of sport-specific skills would allow children to progress on the sport-specific performance scale, it may lead to postural and movement adaptations potentially resulting in long-term physical impairments $[10,12,16]$.

To prevent premature development of sport-specific postural and physical characteristics, children should be encouraged to participate in a range of sporting activities, which would allow for healthy postural and motor control development, especially during early childhood (i.e. before the age of 12) [2, 25]. In the case of young judokas, the rate of motor development is steadier than in healthy controls and may peak at the age of 11-12 and 14-15 years [24]. Hence, although judo participants have demonstrated better physical performance and postural development in this study, care should be taken to continue to diversify their sport participation with judo and physical education classes, as it seems to result in better overall development.

\section{Conclusions}

In conclusion, judo is a recommended activity for children, especially during early childhood when they are encouraged to try different activities. Subsequent benefits to physical characteristics and motor abilities may contribute to performance in various sport activities. As judo is a low cost and easily implemented activity, it may have practical applications across different educational systems, especially in schools that lack resources for sporting equipment.

\section{Disclosure statement}

No author has any financial interest or received any financial benefit from this research.

\section{Conflict of interest}

The authors state no conflict of interest.

\section{References}

1. Ortega FB, Ruiz JR, Castillo MJ, Sjöström M. Physical fitness in childhood and adolescence: a powerful marker of health. Int J Obes. 2008;32(1):1-11; doi: 10.1038/ sj.ijo.0803774.

2. Fransen J, Pion J, Vandendriessche J, Vandorpe B, Vaeyens R, Lenoir M, et al. Differences in physical fitness and gross motor coordination in boys aged 6-12 
years specializing in one versus sampling more than one sport. J Sports Sci. 2012;30(4):379-386; doi: 10.1080/ 02640414.2011 .642808$.

3. Jehle C, Kühnis J. Postural assessment of primary school children in Liechtenstein: a longitudinal study 2008-2010. Schweiz Z Sportmed Sporttraumatol. 2011; 59(3):133-135.

4. Coelho JJ, Graciosa MD, De Medeiros DL, Da Costa LMR, Martinello M, Ries LGK. Influence of nutritional status and physical activity on the posture of children and adolescents. Fisioter Pesqui. 2013;20(2):136-142; doi: 10.1590/S1809-29502013000200007.

5. Witkowski K, Maślinski J, Remiarz A. Static and dynamic balance in 14-15 year old boys training judo and in their non-active peers. Arch Budo. 2014;10:323-331.

6. Jagiełło W, Kalina RM, Tkaczuk W. Development of strength abilities in children and youths. Biol Sport. 2004;21(4):351-368.

7. Barnett LM, van Beurden E, Morgan PJ, Brooks LO, Beard JR. Childhood motor skill proficiency as a predictor of adolescent physical activity. J Adolesc Health. 2009;44(3):252-259; doi: 10.1016/j.jadohealth.2008. 07.004 .

8. Laskowski R, Ziemann E, Grzywacz T. Comparison of aerobic capacity in various groups of adolescent athletes. Arch Budo. 2009;5:21-24.

9. Fukuda DH, Stout JR, Burris PM, Fukuda RS. Judo for children and adolescents: benefits of combat sports. J Strength Cond Res. 2011;33(6):60-63; doi: 10.1519/ SSC.0b013e3182389e74.

10. Balagué F, Nordin M, Skovron ML, Dutoit G, Yee A, Waldburger M. Non-specific low-back pain among schoolchildren: a field survey with analysis of some associated factors. J Spinal Disord. 1994;7(5):374-379; doi: 10.1097/00002517-199410000-00002.

11. Grabara M. Analysis of body posture between young football players and their untrained peers. Hum Mov. 2012;13(2):120-126; doi: 10.2478/v10038-012-0012-7.

12. Abraham A, Sannasi R, Nair R. Normative values for the functional movement screen in adolescent school aged children. Int J Sports Phys Ther. 2015;10(1):29-36.

13. Nishime RS. Martial arts sports medicine: current issues and competition event coverage. Curr Sports Med Rep. 2007;6(3):162-169; doi: 10.1007/s11932-0070023-x.

14. Pion J, Fransen J, Lenoir M, Segers V. The value of nonsport-specific characteristics for talent orientation in young male judo, karate and taekwondo athletes. Arch Budo. 2014;10:147-154.

15. Perrin P, Deviterne D, Hugel F, Perrot C. Judo, better than dance, develops sensorimotor adaptabilities involved in balance control. Gait Posture. 2002;15(2): 187-194; doi: 10.1016/S0966-6362(01)00149-7.

16. Sahrmann S. Movement system impairment syndromes of the extremities, cervical and thoracic spines. St. Louis: Elsevier Mosby; 2011.
17. Lohman TG, Roche AF, Martorell R. Anthropometric standardization reference manual. Champaign: Human Kinetics; 1988.

18. Eurofit: handbook for the Eurofit tests of physical fitness. Strasbourg: Council of Europe; 1993.

19. Wolański N. Physical growth and development with body posture. Warsaw: PZWL; 1975.

20. Wurth BH. Review of the Wolanski gross motor evaluation. Phys Occup Ther Pediatr. 1981;1(2):63-70; doi: 10.1080/J006v01n02_07.

21. Maciałczyk-Paprocka K, Stawińska-Witoszyńska B, Kotwicki T, Sowińska A, Krzyżaniak A, Walkowiak J, et al. Prevalence of incorrect body posture in children and adolescents with overweight and obesity. Eur J Pediatr. 2017;176(5):563-572; doi: 10.1007/s00431017-2873-4.

22. Opstoel K, Pion J, Elferink-Gemser M, Hartman E, Willemse B, Philippaerts R, et al. Anthropometric characteristics, physical fitness and motor coordination of 9 to 11 year old children participating in a wide range of sports. PLoS One. 2015;10(5):e0126282; doi: 10.1371/ journal.pone.0126282.

23. Jaakkola T, Watt A, Kalaja S. Differences in the motor coordination abilities among adolescent gymnasts, swimmers, and ice hockey players. Hum Mov. 2017;18(1):4449; doi: 10.1515/humo-2017-0006.

24. Jagiełło W, Kalina RM. Properties of motor development in young judokas. J Hum Kinet. 2007;17:113-120.

25. Côté J. The influence of the family in the development of talent in sport. Sport Psychol. 1999;13(4):395-417; doi: 10.1123/tsp.13.4.395. 